\title{
Analyzing the Efficient Execution of In-Store Logistics Processes in Grocery Retailing - The Case of Dairy Products
}

(Published in Production and Operations Management in 2013, DOI: 10.1111/poms.12003)

\section{Gerald Reiner}

Institut de l'entreprise, Université de Neuchâtel; Rue A.-L. Breguet 1, CH-2000 Neuchâtel, Switzerland, tel: ++41 (0)32 718 1473; e-mail: gerald.reiner@unine.ch;

\section{Christoph Teller}

Surrey Business School, University of Surrey, GU2 7HX Guildford, United Kingdom, tel: ++44

(0)1483 68 3981, e-mail: c.teller@ surrey.ac.uk;

Herbert Kotzab (corresponding author)

Institute for Logistics and Supply Chain Management, University of Bremen (second affiliation: Caledonian Business School, Glasgow Caledonian University, Glasgow, United Kingdom), 2000 Bremen, Germany, tel.: ++49 (0)421 218 66981, e-mail: kotzab@uni-bremen.de;

Reference of the original article: Reiner, Gerald, Teller, Christoph, Kotzab, Herbert. 2013. Analyzing the Efficient Execution of In-Store Logistics Processes in Grocery Retailing - The Case of Dairy Products. Production and Operations Management, 2 (4), pp. 924-939, DOI: 10.1111/poms.12003.

\section{Non-technical essay}

The efficient execution of the in-store logistics related to fast-moving, sensitive and essential items is challenging, and crucial for grocery retailers' sales, profits and image. This paper insights into the nature of in-store logistics processes related to diary products in different grocery store formats and to suggest a multi-analysis approach to make the performance of in-store logistics processes measureable, comparable and, consequently, manageable. 


\title{
Analyzing the Efficient Execution of In-Store Logistics Processes in Grocery Retailing - The Case of Dairy Products
}

\begin{abstract}
In this paper, we examine in-store logistics processes for handling dairy products, from the incoming dock to the shelves of supermarkets and hypermarkets. The efficient execution of the in-store logistics related to such fast-moving, sensitive and essential items is challenging, and crucial for grocery retailers' sales, profits and image. In our empirical study we survey in-store logistics processes in 202 grocery supermarkets and hypermarkets belonging to a major retail chain in central Europe. Using a data envelopment analysis (DEA) and simulation, we facilitate process benchmarking. In particular, we identify ways of improving in-store logistics processes by showing the performance impacts of different managerial strategies and tactics. The DEA results indicate different efficiency levels for different store formats; the hybrid store format of the small hypermarket exhibits a comparatively worse performance in the analyzed execution of in-store logistics processes. The process simulation analysis reveals that the strategic and tactical design of in-store logistics processes (such as store locations/layouts, capacity management, reorder time, order period and safety stock factors) lead to substantial service performance improvements (such as higher on-shelf availability combined with reduced inventory obsolescence costs). The results also show marginal improvements in the performance figures when delivery delays and damage to products are reduced.
\end{abstract}

Keywords: In-store Logistics, Data Envelopment Analysis, Process Simulation, Grocery Retailing;

History: Original submission: June 2010; 2nd submission: July 2011; 3rd submission: November 2011; 4th submission: July 2012; acceptance: July 2012; by Ananth Raman (Harvard Business School). 


\section{Analyzing the Efficient Execution of In-Store Logistics Processes in Grocery Retailing - The Case of Dairy Products}

\section{Introduction}

Tone (2001) identified retailing as the third phase, after production and logistics, in the flow of goods, and labeled it an important research object for operations and management science research. Fisher (2009) confirmed this view and emphasized that retailing has always been a "favorite context of our field" (p. 527). Generally speaking, managers of retail operations face four issues that affect their success (Fisher 2009): a) the determination of an assortment of products that each store should carry at each point in time; b) the determination of the prices of each of these products; c) the determination of the quantities of each product to be held in inventory; d) eliciting the best efforts from store employees to achieve outstanding store performance. Retail stores are generally described as amalgams of a factory and a sales office, where the role of store employees is to execute processes according to the headquarters' specifications (Fischer 2009). Local store management ultimately determines the success or failure in terms of satisfying customers and influencing patronage behavior favorably (Fisher et al. 2006, Quinn 2006).

Regarding the importance of people for successful store operations, the logistics processes in a retail store can take up more than $40 \%$ of the working hours of store employees and approximately $40 \%$ of the total retail costs (Liebmann and Zentes 2001). This high share of costs is mainly due to the high share of manual activities related to in-store logistics; unfortunately, there are limited possibilities for using technology to execute these processes. Consequently, the impact of in-store logistics on retailers' costs, customer service, and profit can be regarded as significant (Raman et al. 2001a, 2001b, Ton and Huckmann 2005, Fisher et al. 
2006, van Donselaar et al. 2006, 2010, DeHoratius and Raman 2007). However, this part of the store execution processes is still thought of as a 'black box'. Kotzab and Schnedlitz 1999) and has not yet received the academic recognition it deserves.

Considering the limited knowledge of in-store logistics operations within retail stores, the objectives of this paper are as follows: Firstly we aim to structure in-store logistics processes in a framework that can be used to conceptualize and assess them within stores. Secondly we seek to empirically evaluate and quantify these processes and subsequently analyze their efficient execution. Finally we wish to compare in-store logistics across different retail store formats offering different combination of processes that result into different service output levels (Coughlan et al. 2006).

In order to achieve our goals we balance the inputs to an in-store logistics system, all of which are resources that cost money, against the customer service level, measured by the fulfilled customer order. We further draw on Frei and Harker's (1999) critique of previous work that has neglected to examine how inputs are actually transformed into a given output. Consequently, we follow their suggestion of integrating a process design into a performance analysis and thus provide useful managerial recommendations. The tool used for this kind of approach is called data envelope analysis (DEA) - a multifactor, nonparametric productivity analysis technique. It is a powerful tool for the methodical benchmarking of processes and the identification of those that are most efficient and has been proven to accurately measure the efficiency of 'decision-making units' (DMU). It has been widely used in a variety of settings (Tavares 2002, Metters et al. 1999). Recently, Vaz et al. (2010) used DEA to assess the retail efficiency of retailing companies in Portugal. They demonstrated how area, stock, the number of references, and the volume of spoiled products all affect the sales of retail stores. In this paper, 
we focus on the efficiency of in-store logistics processes. To this end, DEA shows, in a quantitative manner, how much a performance indicator would need to improve in order to bring an underperforming logistics process up to the best-practice level. We use DEA to identify "better" DMUs and see this as a prerequisite for our subsequent process simulation analysis, which we use to investigate why different efficiency levels occur.

Comparing only the aggregate inputs (e.g., total store space, floor space and number of employees) and outputs (e.g., turnover, service level and waste) of DMUs does not provide enough advice to inefficient DMUs regarding how to improve their processes. To identify the specific steps needed, in terms of where and how to change processes, requires further detailed analysis based on process simulation. The motivation for this is retail or store managers' desire to measure the efficiency of their stores, compare them with other stores, and identify potential areas of improvement, such as storage, transportation, or order fulfillment activities. Therefore, we analyze whether in-store logistics process modifications (e.g., the pooling of inventory by means of a new layout, i.e., eliminating inventory stages) can lead to improved performance (service level) at a store level.

To summarize, we aim to contribute toward an understanding of the nature of in-store logistics processes and the link between in-store logistics and supply chain efficiency (e.g., enhanced on-time delivery). Additionally, we provide a methodological contribution in the form of performance analysis and improvement, proposing an approach to make the performance of in-store logistics processes measureable, comparable and, consequently, manageable.

The paper is organized as follows. Having described the scope of the paper in this section, we present a literature review in section 2 in order to reveal the research gap that we target in the subsequent argumentation. We then structure typical in-store logistics processes 
related to dairy products within a framework (section 3) and present the methodology we use to measure the efficiency with which these processes are executed (section 4). Section 5 describes the empirical study and the in-store logistics processes surveyed. The next two sections (6 and 7) contain the results of our investigation of process efficiencies for which we applied DEA and process simulation analysis. We present conclusions and implications for theory and practice in section 8 and limitations and future research directions in section 9.

\section{Literature review}

In the following we review the literature related to the execution of store operations from the perspective of in-store logistics. As a result, we identify a research gap that serves as a starting point for our research on in-store logistics processes. Looking at the logistics processes inside a store, Raman et al. (2001a) and Fisher et al. (2000) have demonstrated that poor operations lead to low on-shelf availability; this is a severe problem for the majority of retailers as they tend to operate with very low margins, particularly in the field of grocery retailing (Corsten and Gruen 2003). The main factors include poor at-the-shelf handling and replenishment processes, distribution center processes, store design, store size, so-called 'phantom stockouts' due to products being misplaced in backrooms, storage areas or on the selling floor, a lack of knowledge about real demand and a lack of information concerning the actual number of out-of-stock situations (Raman et al. 2001a, 2001b; Baron et al. 2011). Corsten and Gruen (2003), meanwhile, identified specific logistical upstream drivers related to low onshelf availability in grocery stores, such as store personnel giving the wrong order information and inappropriate shelf stacking. Incorrect order information can be the result of human errors in inventory management decisions at the store level. Raman et al. (2001a) have shown that these types of failures can lead to even larger errors at the distribution center level. 
Turning to shelf stacking - an important part of store operations - Broekmeulen et al. (2004), van Zelst et al. (2008), and Curşeu et al. (2009) have all provided substantial insights into how these specific handling operations impact the performance of grocery retailing. The aspects looked at were shelf-stacking processes and shelf replenishment. Curşeu et al. (2009) pointed out that the stacking of new inventory, the grabbing and opening of case packs, and waste disposal are all critical activities. Stacking and replenishment are very much dependent on the physical dimensions of the products as well as the stores (i.e., shelf dimensions). Proper stacking of shelves can speed up the replenishment process and lower processing costs (Broekmeulen et al. 2004, van Zelst et al. 2008).

The replenishment processes of retail stores also affect performance. Van Donselaar et al. (2006) examined automated product replenishment and how store managers' replenishment orders deviate from those recommended by the replenishment systems. They showed that store managers tend to either consolidate orders or shift them from peak to non-peak days, with store and product characteristics influencing the shifting of orders. Later, van Donselaar et al. (2010) demonstrated how automated store ordering can help to improve inventory replenishment decisions for perishable products and stated that the logistical characteristics of the products (e.g. size, weight, turnover, perishability) have a major influence on the quality of decision making.

Because retail store processes are highly people-intensive, the staff can affect operations positively as well as negatively. Ton and Huckman (2005) demonstrated through their longitudinal study that increased employee turnover is related to decreased store performance, i.e., lower customer service and profit margins. They also found that the wrong incentive schemes for retail store managers can harm the performance of the stores. Later, DeHoratius and Raman (2007) showed that a change in these incentive schemes from a focus on inventory- 
shrinking activities to a focus on sales-generating activities could positively influence the performance of retailing companies.

Within the identified literature on retail store operations, we found that in-store logistics is treated as one of many independent variables with the potential to directly and significantly influence retail store performance. In-store logistics has also been identified as a root cause of products being out-of-stock or not on the shelf, thus indirectly affecting retail store performance. We also identified literature dealing with important aspects of in-store logistics, such as shelfstacking activities and replenishment processes.

Despite these various findings on issues related to in-store logistics as a part of store operations, we were not able to identify any papers that characterized, empirically evaluated and analyzed in-store logistics processes in detail, especially for grocery retail stores. The examined literature does not provide a base-line approach that can be used to assess the performance of instore logistics processes and show areas of improvement. Consequently, we heed the call from the existing literature on store operations and provide in the following sections an in-depth investigation of specific logistics processes at the store level.

\section{Logistics processes within retail stores}

To facilitate the investigation of in-store logistics systems, this chapter presents a framework that can help us to categorize, describe and analyze the considerable number of instore logistics processes that go on in retail stores, particularly but not exclusively related to dairy products. We define all processes related to the replenishment, disposal and recycling of products in retail stores as in-store logistics processes. Such processes vary for different product categories and store formats in terms of extent and the activities involved. 
In order to describe and categorize these processes, we focus on those concerning dairy products, as they are considered the most challenging and sophisticated within retail outlets (Lit et al. 2012). Ferguson and Ketzenberg (2006) and Li et al. (2012) consider the execution of instore logistics processes to be particularly challenging when dealing with fresh and perishable products. Dairy products are an example of the "low-price but high-stock-out-cost item" (Raman et al. 2001a, p. 152), with specific logistical requirements, such as temperature, pressure, a perishable nature, and a high turnover. The dairy product category usually includes the following sub categories: the white category (e.g., fresh milk, whole milk, curd cheese, yogurt and cream); the colored category (e.g., fruit yogurt, curdled milk with fruit, milk-mix drinks and fresh desserts); the yellow category (e.g., hard cheese, cut cheese, soft cheese and cream cheese); the yellow fat category (e.g., butter, margarine and butter oil). Sales in this category represent around $10 \%$ of all grocery sales in Western retail markets. Dairy products are "customer frequency drivers" since consumers must buy them frequently, due to dairy's short lifespan, and the integral role they play in Western diets (van Donselaar 2006, 2010). Therefore, the availably of dairy products in store is a major concern for retailers.

In order to categorize in-store logistics and set up a descriptive framework, we identify the core processes, as suggested by Fisher (2009). As depicted in Table 1, we further differentiate sub-processes that support the shelf-filling processes, as suggested by Broekmeulen et al. (2004), van Zelst et al. (2008) and Curşeu et al. (2009). All these in-store logistics processes depend on (stochastic) customer demand and the replenishment processes earlier in the supply chain. 
Table 1: In-store logistics processes for dairy products

\begin{tabular}{|c|c|}
\hline Sub-processes for dairy products & Process description \\
\hline Receipt/inspection & $\begin{array}{l}\text { Products are delivered on roll cages and pallets, either } \\
\text { from one of the retailer's distribution centers (DC) or } \\
\text { from the DC of a logistics service provider/vendor, } \\
\text { arriving in the receipt area of the store. Store personnel } \\
\text { take over and control the delivery. At this point, return } \\
\text { activities can also take place in the event that the } \\
\text { delivered products do not meet the order specifications. }\end{array}$ \\
\hline $\begin{array}{l}\text { Transportation of tertiary } \\
\text { packaging units to back room } \\
\text { storage facilities or directly to } \\
\text { shelves }\end{array}$ & $\begin{array}{l}\text { Incoming goods are either moved directly to the shelves } \\
\text { or to a specific temporary storage area. }\end{array}$ \\
\hline $\begin{array}{l}\text { Storage of tertiary packaging units } \\
\text { in back room storage facilities }\end{array}$ & $\begin{array}{l}\text { Additional stock that is not placed on the shelves is stored } \\
\text { in the back room storage area. }\end{array}$ \\
\hline $\begin{array}{l}\text { Transportation from back room } \\
\text { storage area to shelves }\end{array}$ & $\begin{array}{l}\text { The movement of products from the back room storage } \\
\text { area to the shelves. }\end{array}$ \\
\hline $\begin{array}{l}\text { Handling and storing of stock- } \\
\text { keeping units on shelves }\end{array}$ & $\begin{array}{l}\text { This aspect includes all the activities that are needed to } \\
\text { achieve shelf replenishment, such as break bulk of } \\
\text { transportation units to end-user units, shelf stacking, and } \\
\text { product presentation (visual merchandising). This process } \\
\text { also includes inventory control, in order to generate re- } \\
\text { ordering and replenishment. }\end{array}$ \\
\hline Re-ordering & $\begin{array}{l}\text { As a result of constantly checking all flows of products } \\
\text { (incoming/outgoing) and the inventory, new orders can be } \\
\text { written up and dispatched to headquarters or a vendor. }\end{array}$ \\
\hline Disposal/recycling & $\begin{array}{l}\text { This includes either the removal of packaging material or } \\
\text { the disposal or recycling of damaged/broken products. It } \\
\text { also generates information that is needed for order } \\
\text { management. Finally, it includes the re-channeling of } \\
\text { packaging and transportation units. }\end{array}$ \\
\hline
\end{tabular}

Other influential factors are the characteristics of the products (e.g., weight, size, quantity, value, perishable nature), and of the retail stores (e.g., location or store layout) (Li et al. 2012). These factors and the in-store logistics processes listed above will occur in any format of grocery store, including convenience stores, supermarkets and hypermarkets . 


\section{Methodology}

\subsection{Measuring the efficiency with which in-store logistics processes are carried out}

In the following paragraphs, we present our method for measuring in-store logistics process efficiency using DEA, which is the most widely used programming method for measuring the productivity of decision making units (DMUs). It is a mathematical programming technique that provides upper-bound estimates of the actual total factor productivity (which can be divided into technical efficiency and technological changes) of DMUs, as well as estimates of the production frontiers (Sudit 1995).

The ratio of the weighted sum of the outputs to the weighted sum of the inputs measures the efficiency of a unit. Then, the efficiency of each unit is evaluated relative to the other units. The underlying procedure is based on a mathematical programming approach. It is not necessary to set weights for this multi-criteria method as the optimal weights are calculated internally. Thus, it is possible to obtain a quite objective evaluation of efficiency that can be used to identify 'best practice' DMUs, This total factor productivity enables management to answer questions such as, "Are the processes of store A more efficient than the processes of store B?" To answer this question the following information is available: The stock turnover in store A is four times as high as that in store B. Nonetheless, the delivery service (e.g., measured by the number of stock-outs) is four times lower in store A than in store B. As these figures do not obviously show which store is more efficient, it is crucial for the identification of "best practices" to compare their stores based on calculated total factor productivity.

The basic model used in DEA is known as the Charnes, Cooper and Rhodes (CCR) model, developed by Charnes et al. (1978). Illustrated below is the dual model of the CCR, which is often preferred over the primal model in calculations. $\theta$ is the aggregate efficiency score 
for $\mathrm{DMU}_{\mathrm{o}}$, the in-store logistics process under observation; $\mathrm{y}_{\mathrm{r} 0}$ is the output $\mathrm{r}$ that is generated by DMU $\mathrm{x}_{\mathrm{i} 0}$ is the input $\mathrm{i}$ that is used by DMU $; \mathrm{X}_{\mathrm{j}}=\left(\mathrm{x}_{1 \mathrm{j}}, \mathrm{x}_{2 \mathrm{j}}, \ldots ., \mathrm{x}_{\mathrm{mj}}\right)$ is the vector of actual inputs used by DMUO. $\mathrm{Y}_{\mathrm{j}}=\left(\mathrm{y}_{1 \mathrm{j}}, \mathrm{y}_{2 \mathrm{j}}, \ldots . ., \mathrm{y}_{\mathrm{sj}}\right)$ is the vector of actual outputs generated by DMUo. $s_{i}^{+}$is the amount of slack in input $\mathrm{i}$ for DMU $; s_{r}^{-}$is the amount of slack in output $\mathrm{r}$ for $\mathrm{DMU}_{\mathrm{o}} ; \lambda_{\mathrm{j}}$ is the dual multiplier (i.e., the weights assigned to the inputs and outputs of $\mathrm{DMU}_{\mathrm{j}}$ ); $\mathrm{s}$ is the number of outputs; $\mathrm{n}$ is the number of DMUs; and $\mathrm{m}$ is the number of inputs.

$$
\begin{array}{cll}
\min _{\lambda_{j}, \theta, s_{i}^{+}, s_{r}^{-}} & \theta-\left(\sum_{i=1}^{m} s_{i}^{+}+\sum_{r=1}^{s} s_{r}^{-}\right) & \\
\text {s.t. } & & \\
& \sum_{j=1}^{n} X_{j} \lambda_{j}+s_{i}^{+}=\theta x_{i 0}, & \forall i=1, \cdots, m \\
& \sum_{j=1}^{n} Y_{j} \lambda_{j}-s_{r}^{-}=y_{r 0}, & \forall r=1, \cdots, s \\
\theta, \lambda_{j}, s_{i}^{+}, s_{r}^{-} \geq 0, & \forall i, r, j
\end{array}
$$

The CCR model assumes constant returns to scale. However, in the context of in-store logistics processes, it is not appropriate to assume that all DMUs are operating at the optimal scale (e.g., imperfect information flows, an imperfect layout or constraints on resources could prevent this). Therefore, we use the Banker, Charnes and Cooper (BBC) model, which assumes variable returns to scale. Models with variable returns to scale take the form of technical efficiency or scale efficiency. They differ from the CCR model through the additional of the following constraint (Banker et al. 1984): 


$$
\sum_{j=1}^{n} \lambda_{j}=1
$$

The BCC model calculates technical efficiency while the CCR model evaluates aggregated ratios for both technical and scale efficiency. Constraint (5) ensures that an inefficient DMU is only benchmarked against DMUs of a similar size while the use of the CCR model could mean DMUs are being benchmarked against much smaller or larger DMUs.

A DMU is called efficient if the following is true of the optimal solution:

(i) $\theta=1$ and

(ii) all slack variables $s_{i}^{+}, s_{r}^{-}$equal zero.

1- $\theta$ is the proportion by which all inputs must be reduced in order for the DMU to be efficient. Therefore, the value of $\theta$ is a radial efficiency measure (i.e., it deals with proportional improvements in inputs and outputs).

DEA is a valuable tool, not only for classifying DMUs using efficiency measures, but also for finding inefficient units with the potential for improvement. Each inefficient DMU $(\theta<1)$ has a reference set of efficient DMUs (Cooper et al. 2007). A reference set is an efficiency frontier that consists of linear combinations of the efficient DMUs.

The weights of the input and output variables used to calculate the efficiency values are unlimited. This arrangement leads to a problem, in that some enterprises focus on a limited number of input and output variables and, thus, derive efficiency values that are too high (Talluri and Baker 2002). In order to obtain a more systematic evaluation of a unit's performance, we specify weight restrictions of the form $\mathrm{W}(\mathrm{p}, \mathrm{q}) \geq 0$, where $\mathrm{p}$ is the vector of input weights and $\mathrm{q}$ is 
the vector of output weights (Scheel 2001). In formula (6), $\mathrm{L}_{1,2}$ and $\mathrm{U}_{1,2}$ are the lower and upper bounds on the ratio $\mathrm{p}_{1} / \mathrm{p}_{2}$ (Cooper et al. 2007).

$$
L_{1,2} \leq \frac{p_{1}}{p_{2}} \leq U_{1,2}
$$

To address this problem, we follow Roll et al. (1991) and introduce appropriate limits on the weights. First, we calculate the efficiency values without constraints using the BCC DEA. Next, we set constraints in such a way that weights that are virtually zero are eliminated but the remaining weights are not changed or constrained. The approach of Roll et al. (1991) is a compromise that attempts to prevent extreme values (e.g., zero values for weights).

In the context of this paper, we treat each retail store as a DMU. Consequently, we restrain these DMUs using factors such as store layout, management pre-setting (inventory policies, etc.), IT infrastructure, etc. Using the approach of Roll et al. (1991), we set the lower limit for the marginal rate of substitution of each combination of weights for the input and output variables arbitrarily at 0.1 and the upper limit at 10 (Reiner and Hofmann 2006).

\subsection{Process analysis based on simulation of the execution of in-store logistics processes}

As mentioned above, DEA is a valuable tool for classifying DMUs using efficiency measures and for identifying potential improvements. A major limitation of DEA in this context is missing knowledge about the so-called 'production function', that is, it is not obvious how the inputs are turned into outputs. In particular, the process physics (flows) are not investigated under DEA. To overcome this problem and so as to provide more specific managerial implications, we use process simulation (also known as empirical quantitative modeling). 
In this paper we present a quantitative model using empirical data, that is, we model 'real' in-store logistics processes with a complexity that is close to reality. Davis et al. (2007) and Bertrand and Fransoo (2002) point out that quantitative, model-driven empirical research offers a great opportunity to further theory development by generating models of causal relationships between control variables and performance variables. Thus, in our study, we use normative empirical quantitative research to develop strategies and policies and identify potential improvements so as to overcome the limitations of DEA.

\section{Empirical study}

\subsection{Research design}

In these next two sections we elaborate on our empirical research design and the characterization of the investigated in-store logistics processes. We gathered the empirical data for our analysis by assessing the in-store logistics processes of the dairy departments of the stores of a leading European grocery retailer located in a highly-concentrated retail market. The sample represents the three dominant grocery store formats and includes 147 supermarkets with floor space between 400 and 1000 meters squared, 36 small hypermarkets $(1,000$ - 2,999 meters squared) and 19 large hypermarkets (> 3,000 meters squared). We surveyed store or category managers, who served as informants, since they were deemed to have the best knowledge of the in-store logistics processes. An interviewer-administered questionnaire was used to gather structured insights into these processes. This included 65 questions (open/closed; metric/ordinal scales) that were used to quantify all of the in-store logistics processes shown in Table 1. The survey had three parts: (1) an assessment of the store dimensions and transit times within the store, in order to characterize the input/output relationships; (2) an evaluation of in-store logistics process execution; (3) the identification of specific problem areas. 


\subsection{Characterization of in-store logistics processes and related issues}

The empirical characterization of the examined in-store logistics processes is presented in Table 2. The results showed fairly heterogeneous characteristics of processes among the three formats (see significant differences $(\Delta)$ ). Problematic issues include the lack of delivery accuracy from the DC, the disposal or recycling of spoiled or broken products, and the partial inapplicability of automated ordering systems.

Our evaluation of the in-store logistics processes revealed that dairy products are delivered daily to all stores. The delivery times are usually outside the regular store opening hours, and the dairy products are delivered alongside other fresh products. The majority of the dairy products that arrive at the store chilled, and the respondents indicated that the delivery process does not affect the other in-store logistics processes. The staff inspects the incoming items by comparing the information on the order form with that on the delivery note. 
Table 2: In-store logistics process and structural measures

\begin{tabular}{|c|c|c|c|c|c|c|c|c|}
\hline \multicolumn{9}{|l|}{ Structural measures } \\
\hline \multirow{2}{*}{$\begin{array}{l}\text { Store format } \\
\text { Characteristics }\end{array}$} & \multicolumn{2}{|c|}{ Supermarket } & \multicolumn{2}{|c|}{$\begin{array}{c}\text { Small } \\
\text { hypermarket }\end{array}$} & \multicolumn{3}{|c|}{$\begin{array}{c}\text { Large } \\
\text { hypermarket }\end{array}$} & \multirow[t]{2}{*}{$\Delta$} \\
\hline & $\mu$ & $\sigma$ & $\mu$ & $\sigma$ & \multicolumn{2}{|c|}{$\mu$} & $\sigma$ & \\
\hline $\begin{array}{l}\text { Total store space } \\
\left(\mathrm{m}^{2}\right)\end{array}$ & 685.9 & 240.4 & $1,876.8$ & 63 & \multicolumn{2}{|c|}{5,010} & 1,470 & $\mathrm{a} / \mathrm{b} / \mathrm{c}$ \\
\hline Floor space $\left(\mathrm{m}^{2}\right)$ & 504.4 & 143.8 & $1,419.4$ & 398 & \multicolumn{2}{|c|}{$4,303.4$} & $0,40.8$ & $a / b / c$ \\
\hline Number of staff & 18.1 & 18.4 & 32.4 & 14. & \multicolumn{2}{|c|}{60.8} & 25.9 & $a / b / c$ \\
\hline $\begin{array}{l}\text { Width of chilled } \\
\text { cabinets (shelves) } \\
\text { (m) }\end{array}$ & 10.2 & 11.6 & 15.7 & 4.6 & \multicolumn{2}{|c|}{34.8} & 16.1 & $\mathrm{a} / \mathrm{b} / \mathrm{c}$ \\
\hline $\begin{array}{l}\text { Number of stock } \\
\text { keeping units within } \\
\text { the dairy category }\end{array}$ & 309.5 & 224.3 & 412.9 & 182 & \multicolumn{2}{|c|}{757.4} & 117.1 & $\mathrm{a} / \mathrm{b}$ \\
\hline \multicolumn{9}{|l|}{ Process measures } \\
\hline \multirow{2}{*}{\multicolumn{2}{|c|}{ Store format }} & \multicolumn{2}{|c|}{ Supermarket } & \multicolumn{2}{|c|}{$\begin{array}{c}\text { Small } \\
\text { hypermarket }\end{array}$} & \multicolumn{2}{|c|}{$\begin{array}{c}\text { Large } \\
\text { hypermarket }\end{array}$} & $\Delta$ \\
\hline & & $\mu$ & $\sigma$ & $\mu$ & $\sigma$ & $\mu$ & $\sigma$ & \\
\hline \multicolumn{2}{|c|}{ Inspection time (minutes) } & 23.0 & 23.1 & 33.3 & 32.8 & 21.1 & 15.0 & $\mathrm{a} / \mathrm{c}$ \\
\hline \multicolumn{2}{|c|}{$\begin{array}{l}\text { Distance between area to which } \\
\text { products are delivered and cold } \\
\text { room (back room storage } \\
\text { facility) (m) }\end{array}$} & 21.8 & 37.4 & 39.3 & 107.1 & 20.7 & 18.5 & - \\
\hline \multicolumn{2}{|c|}{$\begin{array}{l}\text { Distance between cold room and } \\
\text { chilled cabinets }(\mathrm{m})\end{array}$} & 22.9 & 37.7 & 50.9 & 95.7 & 37.5 & 50.4 & $\mathrm{a} / \mathrm{b}$ \\
\hline \multicolumn{2}{|c|}{$\begin{array}{l}\text { Distance between area to which } \\
\text { products are delivered and } \\
\text { chilled cabinets }(\mathrm{m})\end{array}$} & 33.7 & 43.7 & 87.9 & 178 & 60.2 & 68.3 & $\mathrm{a} / \mathrm{b}$ \\
\hline \multicolumn{2}{|l|}{ Storage space $\left(\mathrm{m}^{2}\right)$} & 11.3 & 5.9 & 17.4 & 10.3 & 27.0 & 17.6 & $\mathrm{a} / \mathrm{b} / \mathrm{c}$ \\
\hline \multicolumn{2}{|c|}{$\begin{array}{l}\text { Storage time for white dairy } \\
\text { category (hours) }\end{array}$} & 10.9 & 11.2 & 20.4 & 17.6 & 10.2 & 12.1 & $\mathrm{a} / \mathrm{b} / \mathrm{c}$ \\
\hline \multicolumn{2}{|c|}{$\begin{array}{l}\text { Time for shelf replenishment } \\
\text { (hours/day) }\end{array}$} & 2.7 & 2.2 & 4.7 & 2.5 & 6.4 & 4.7 & $\mathrm{a} / \mathrm{b}$ \\
\hline \multicolumn{2}{|c|}{$\begin{array}{l}\text { Total number of staff hours } \\
\text { spent on shelf replenishment } \\
\text { (hours/day) }\end{array}$} & 4.1 & 3.7 & 8.8 & 6.8 & 14.3 & 10.4 & $\mathrm{a} / \mathrm{b} / \mathrm{c}$ \\
\hline \multicolumn{2}{|c|}{$\begin{array}{l}\text { Waste share in the category per } \\
\text { day (\%/day) }\end{array}$} & 1.2 & 3.6 & 1.5 & 2.5 & 0.7 & 0.9 & - \\
\hline \multicolumn{2}{|l|}{ Orders per week } & 5.9 & 0.4 & 5.8 & 0.4 & 5.6 & 1.0 & $b$ \\
\hline
\end{tabular}


All of the examined stores have a cold room in addition to chilled cabinets (shelves). Dairy products are stored there for an average of 12.5 hours $(\sigma=13)$ before being moved to shelves in the store. The distance between the area to which the products are delivered and the cold room is, on average, 24.6 meters $(\sigma=54.8)$, and the distance between the cold room and the shelves is 29.1 meters $(\sigma=54.3)$. The most frequent issue regarding in-store logistics is the movement of products within stores. Almost every second store $(44.1 \%)$ reported having a suboptimal physical structure or obstacles, such as an unacceptable number of steps, narrow aisles or poor floor conditions. Breaking down the tertiary packaging into consumer-specific units and putting items on shelves takes an average of $3.3(\sigma=2.9)$ hours per day and ties up a lot of human resources in the stores. In terms of the disposal and recycling of dairy products, we looked at the share of articles removed because they have reached their expiration date. About $1.2 \%$ of all articles $(\sigma=3.2)$ have to be disposed of for this reason, with fresh milk and whipped cream the most frequently discarded items. Whipped cream, plain yogurt, and sour cream are the items that are most often affected by damage (e.g., the aluminum lid covering the beaker gets torn). Dairy products are ordered daily, except by the larger hypermarkets that hold larger quantities of stock. Ordering takes an average of $38.2(\sigma=26.6)$ minutes per day.

Comparing the measures between formats, we can see that there are significant variations except the distance between the area to which the products are delivered and the cold room (meters) and the waste share in the category per day (Mann-Whitney U-Test; $\mathrm{p}<0.05$ ). Overall, these findings show that the retail store-level supply chain and operations processes are heterogeneous across different store formats. The presented data are subsequently used in the DEA and the simulation-based process analysis. 


\section{DEA application}

\subsection{Input and output variables}

This section explains the application and outcome of the DEA. Before applying DEA, it is necessary to determine relevant input and output variables. Based on Clarke and Gourdin's (1991) conceptual model of logistics systems, we identified the following variables (see Figure 1):

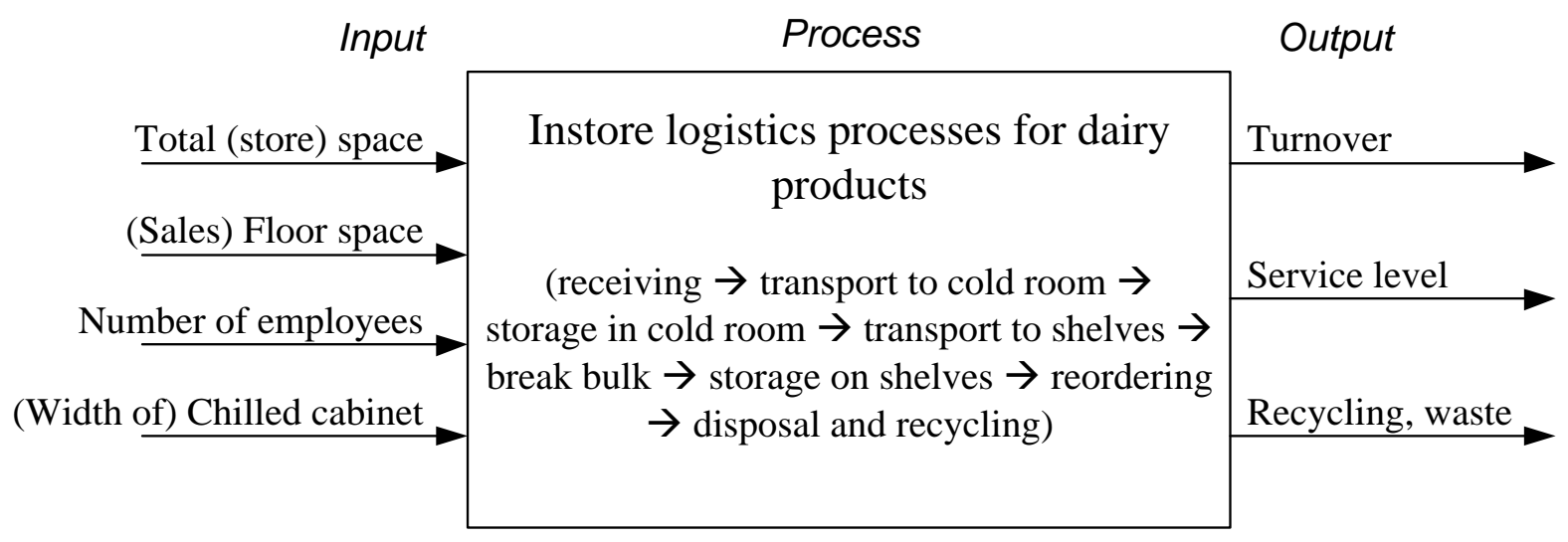

Figure 1. Inputs and outputs of efficient in-store logistics processes for dairy products

The input variables include space, staff and shelf measures, while the outputs are measures of turnover, service level and disposal/recycling. Items were adapted from Scheel (2001) to measure the service level and disposal/recycling. However, for DEA, one must choose inputs and outputs such that a reduction of inputs or an increase of outputs will lead to an increase in the efficiency value. The disposal/recycling measure did not meet this requirement so we transformed it using the ratings from respondents who specified the share of recycled products for each subcategory. Another problem with these two measures is typical for measures that contain percentages or rating scales. Dyson et al. (2001) suggest the use of normalized outputs (scaling the output values by input variables that serve as indicators for the physical size of a DMU). Thus we used the width of the chilled cabinets as a scaling factor (or structural 
variable) in order to meet the requirements of a DEA. Table 3 lists both input and output measures in detail.

Table 3: DEA inputs and outputs

\begin{tabular}{|c|c|}
\hline Inputs & Calculation \\
\hline Total (store) space & Floor space in $\mathrm{m}^{2}$ \\
\hline (Sales) floor space & Floor space in $\mathrm{m}^{2}$ that is accessible to customers \\
\hline Number of employees & $\begin{array}{l}\text { Equivalent full-time employed individuals: \#full time } \\
+ \text { \#part time } * 0.5+\text { \#apprentices + \#marginally } \\
\text { employed } * 0.2\end{array}$ \\
\hline $\begin{array}{l}\text { (Width of ) chilled cabinet } \\
\text { (shelves) }\end{array}$ & Width of chilled cabinet for dairy products in $\mathrm{m}$ \\
\hline \multicolumn{2}{|l|}{ Outputs } \\
\hline Turnover & Turnover $=1 /$ storage time for dairy products \\
\hline Service level & $\begin{array}{l}\text { Frequency of out-of-stock situations according to a } \\
\text { rating scale (1...very frequently and } 5 \ldots \text { never) } * \\
\text { structural variable (width of shelves in } \mathrm{m})\end{array}$ \\
\hline Disposal/recycling & $\begin{array}{l}(100-\text { (estimated share of products to be recycled } \\
\text { because of a low/old best before date) } * \text { structural } \\
\text { variable (width of shelves in } \mathrm{m})\end{array}$ \\
\hline
\end{tabular}

Table 4 shows the specifications of the investigated DEA models. Basically, only the BCC models including or excluding weight limitations were estimated. The total store and floor space were treated as "non-discretionary" measures (ND) (i.e., cannot be manipulated by management) (Banker and Morey 1986). 
Table 4: Alternative DEA models

\begin{tabular}{lll}
\hline & Model 1 & Model 2 \\
\hline $\begin{array}{l}\text { DEA model } \\
\text { Weight limitations }\end{array}$ & BCC & NCC \\
$\begin{array}{l}\text { Input measures } \\
\text { Total (store) space }\end{array}$ & ND & YES \\
(Sales) floor space & ND & ND \\
$\begin{array}{l}\text { Number of } \\
\text { employees }\end{array}$ & D & ND \\
(Width of) chilled & D & D \\
cabinets & & \\
\hline Output measures & & \\
\hline Turnover & D & D \\
$\begin{array}{l}\text { Service level } \\
\text { Disposal/recycling }\end{array}$ & D & D \\
\hline Notes: & D \\
ND...non-discretionary input/output measures \\
D...discretionary input/output measures
\end{tabular}

\subsection{DEA results}

The main result for each DEA model is a distribution of the stores across six ranges of efficiency values (see Figure 2). The left-hand column shows the distribution of efficiency measures across all three formats combined. The next three columns show the results for each of the three formats separately (both absolute and relative) are shown for each value range in order to provide the basis for the subsequent process analysis. Model 1 was estimated without weight constraints and shows no clear distinction between the DMUs since around 35\% have an efficiency value of 1 . Thus, this analysis represents a test to detect extreme values, that is DMUs that perform significantly worse than the others (i.e., with an efficiency value of $<1$ ). 


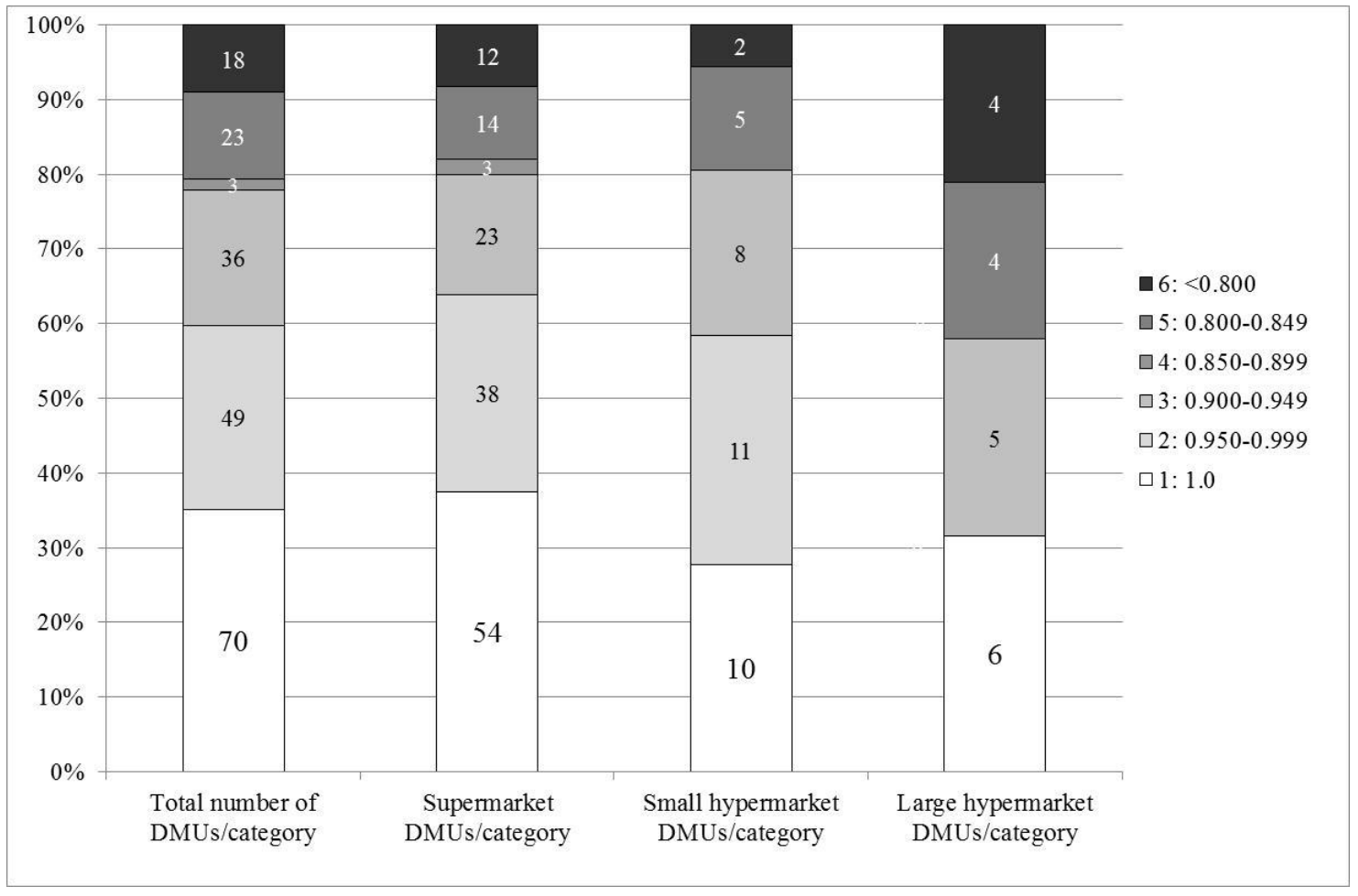

Figure 2: DEA results (Model 1)



Figure 3: DEA results (Model 2) 
Model 2 includes weight constraints and appears to provide much more relevant results because the weakness of some variables cannot be completely compensated by the strengths of others. Figure 3 shows a significantly smaller number of efficient DMUs with values of 1 . The spread of efficiency values has increased, with most (absolute number) of the efficient DMUs belonging to store format supermarket. Formats supermarket and large hypermarket both include more efficient DMUs than format small hypermarket.

This core finding from the DEA leads us to the proposition that lower efficiency can be caused by different formats or even variations within formats. In particular, the distance in meters between the area where product deliveries are received and the cold room is significantly greater for format small hypermarket than it is for the other formats as is the distance between this area and the shelves (see Table 2).

The most important limitation of DEA is that no process-related reasons are provided for the inefficiencies (low efficiency scores). It is possible to generate insights and develop propositions but verification (or rejection) is not possible. Consequently, we conducted a process analysis in order to investigate, for example the low efficiency figures of small hypermarkets, in more detail. This also enabled us to test different process alternatives (e.g., pooling space by extending the space in the chilled cabinets and simultaneously eliminating the space in cold rooms).

\section{Simulation-based process analysis of in-store logistics systems}

The process simulation described below deals with the proposition we developed above based on the DEA, that significantly lower efficiency can be caused by different formats and configurations. Due to the unsteady state of the model in our estimation framework, it was not 
possible to use axiomatic research. Consequently, we applied a dynamic process simulation (that is, we consider demand volatility and operative risks, based on our empirical data). Bertrand and Fransoo (2002) provide an overview of this approach in which they employ quantitative models based on empirical data. We modeled the relevant logistics processes by using a discrete-event simulation tool (ProcessModel, Version 5). Figure 4 illustrates the process simulation (i.e., the configuration of the process, such as buffers and activities), as well as the product and information flow and the resource allocation. When focusing on resource allocation, we looked only at fresh milk (i.e., a high-turnover, perishable product that is sensitive to packaging) in detail. Within the simulation model, however, we allocated resources to all store products on an aggregated level in order to provide realistic utilization settings.

First, we specified the input parameters of the process simulation model. These variables came from discussions with the managers as well as our direct observations of the process during the empirical study. One of the most important input parameters for the simulation model is the distribution of customer demand of dairy products, $\mathrm{CO}_{\mathrm{t}}$. Based on additional information related to milk replenishment provided by the retail chain, we assumed demand followed a triangular distribution with parameters as given in Table 5.

Table 5: Estimates of $\mathrm{CO}_{\mathrm{i}}$ in liters per week (i)

\begin{tabular}{lccc}
\hline \multicolumn{1}{c}{ Demand [1] } & $\min$ & $\bmod$ & $\max$ \\
Store format & 100 & 180 & 250 \\
Supermarket & 180 & 250 & 350 \\
Small hypermarket & 250 & 300 & 500 \\
Large hypermarket & \multicolumn{4}{l}{ Notes: min = minimum; $\bmod =$ mode; $\max =$ maximum } \\
\hline
\end{tabular}




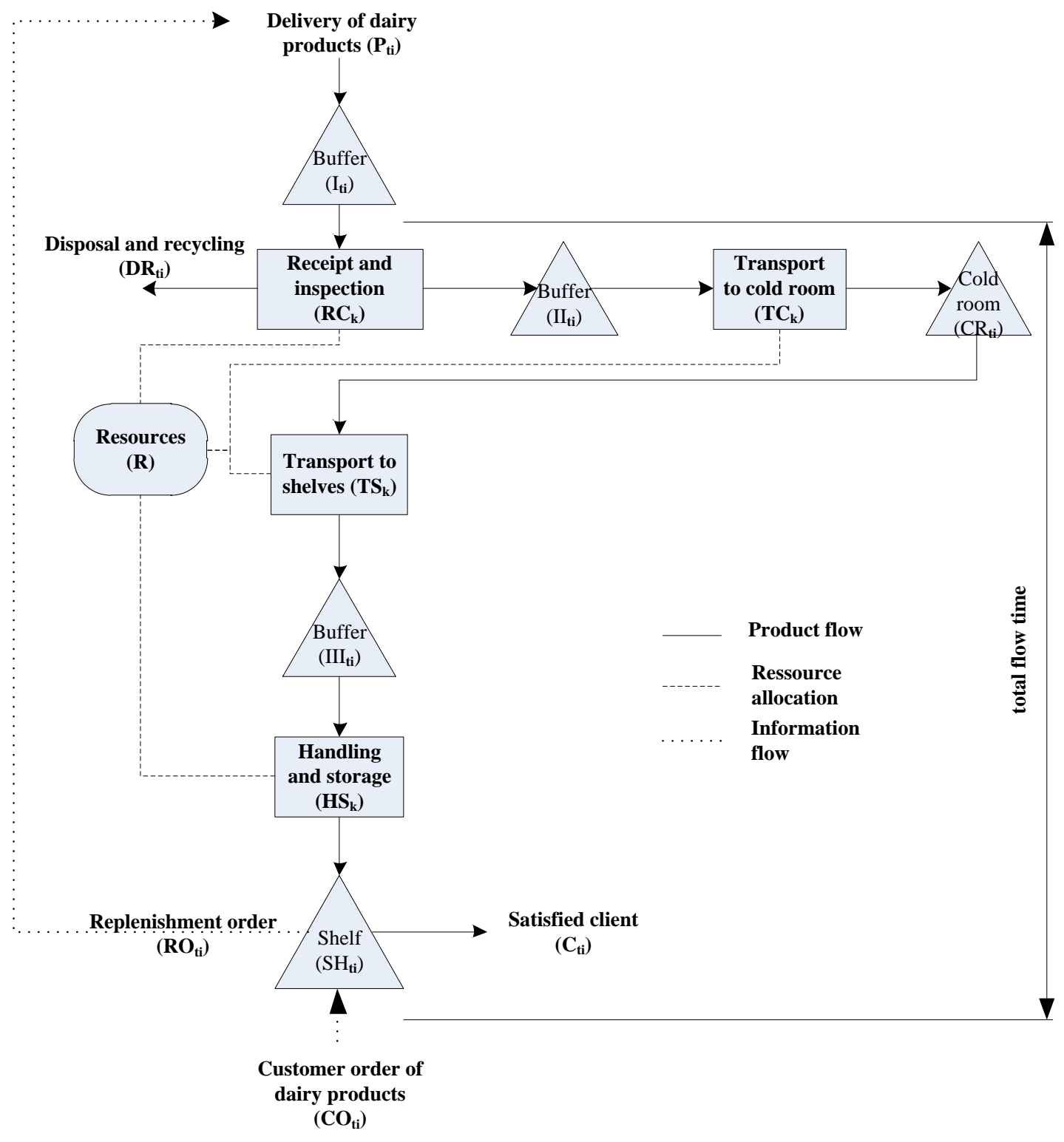

Figure 4: Standard process simulation model

In addition, we considered the dynamic aspects over the course of the week, that is different demand on different weekdays (see Table 6). In the simulation model, the demand for each day was estimated according to the parameters in Table 5 but then multiplied by the daily weights. 
Table 6: Daily distribution of $\mathrm{CO}_{\mathrm{ti}}$ over the course of week $\mathrm{i}$

\begin{tabular}{|c|c|c|c|c|c|c|}
\hline Weekday & $\begin{array}{c}\mathrm{MON} \\
(\mathrm{t}=1)\end{array}$ & $\begin{array}{l}\text { TUE } \\
(\mathrm{t}=2)\end{array}$ & $\begin{array}{l}\text { WED } \\
(\mathrm{t}=3)\end{array}$ & $\begin{array}{l}\text { THU } \\
(\mathrm{t}=4)\end{array}$ & $\begin{array}{r}\text { FRI } \\
(\mathrm{t}=5)\end{array}$ & $\begin{array}{l}\text { SAT } \\
(\mathrm{t}=6)\end{array}$ \\
\hline Sup & 0.18 & 0.15 & 0.15 & 0.15 & 0.19 & 0.18 \\
\hline Small & 0.1 & 0.14 & 0.13 & 0.15 & 0.22 & 0.18 \\
\hline Large hypermarket & 0.18 & 0.14 & 0.13 & 0.15 & 0.22 & 0.18 \\
\hline
\end{tabular}

Other input parameters included the number of employees $(\mathrm{R})$, transportation time for each product $(\mathrm{k})$ relative to the distance travelled $\left(\mathrm{TC}_{\mathrm{k}}, \mathrm{TS}_{\mathrm{k}}\right)$, and manipulation time (inspection of incoming products to check that they are in accordance with the delivery documents and quality standards, $\mathrm{RC}_{\mathrm{k}}$; shelf replenishment, $\mathrm{HS}_{\mathrm{k}}$ ). We made stochastic assumptions about the manipulation and shelf replenishment times based on our observations (see Table 7).

The output parameters of the process simulation included the flow time of the cold room (CR), the total flow time (beginning with the inspection of incoming products, $\mathrm{RC}_{\mathrm{k}}$, and ending with selection by the customer and subsequent removal from the shelves), the level of stock on the shelf, and the share of products $(\mathrm{k})$ with a flow time of more than 72 hours. These parameters were included in the analysis and comparison of the formats. 
Table 7: Process simulation - input parameters

$\mathrm{R}$

Store format

Supermarket

Small hypermarket

Large hypermarket

$\mathrm{RC}_{\mathrm{k}}$

Store format

Supermarket /

Small hypermarket /

Large hypermarket

\section{$\mathrm{DR}_{\mathrm{ti}}$}

Store format

Supermarket /

Small hypermarket /

Large hypermarket

\begin{tabular}{|c|c|c|c|c|c|}
\hline Store format & $\mathrm{TC}_{\mathrm{k}}$ & distribution & mean $[1$ & in/batch] & $\begin{array}{l}\text { tandard deviation } \\
{[\mathrm{min} / \mathrm{batch}]}\end{array}$ \\
\hline Supermarket & & normal & & .3 & 2.2 \\
\hline Small hypermarket & & normal & & .4 & 4.4 \\
\hline Large hypermarket & & normal & & .7 & 0.9 \\
\hline Store format & $\mathrm{TS}_{\mathrm{k}}$ & distribution & mean $[1$ & in/batch] & $\begin{array}{l}\text { tandard deviation } \\
{[\mathrm{min} / \mathrm{batch}]}\end{array}$ \\
\hline Supermarket & & normal & & 2 & 1.8 \\
\hline Small hypermarket & & normal & & 1 & 4.2 \\
\hline Large hypermarket & & normal & & 0 & 1.8 \\
\hline Store format & $\mathrm{HS}_{\mathrm{k}}$ & distribution & $\min [\min /$ batch $]$ & $\operatorname{mode}[\mathrm{min} / \mathrm{batch}]$ & $\max [\min / \mathrm{batch}]$ \\
\hline $\begin{array}{l}\text { Supermarket / } \\
\text { Small hypermarket / } \\
\text { Large hypermarket }\end{array}$ & & triangular & 0.5 & 4 & 10 \\
\hline
\end{tabular}

Number of employees
13

19
$\mathrm{RC}_{\mathrm{k}} \quad$ User-defined distribution: $\mathrm{Dz}(\mathrm{a} 1, \mathrm{~b} 1, \mathrm{a} 2, \mathrm{~b} 2, \ldots)$ $\mathrm{z}=$ number of possible outcomes, $\mathrm{a}=$ percentage, $\mathrm{b}=$ value

D11(12,5,20,10,17,15,11,20,1,25,21,30,0.5,35, $0.5,45,7,60,7,90,3,120)[\mathrm{min} / \mathrm{batch}]$

User-defined distribution

D13(62.5,1,9.1,2,3.4,3,0.6,4,9.7,5,1,8,8.6,10, $0.6,12,0.6,13,0.6,15,1.7,20,0.6,25,0.6,30)[\%]$ 
- $\quad$ The maximum package size is assumed to be one liter.

The main aims of the process analysis are to investigate reasons for the inefficiencies identified in the DEA and identify potential improvements. Consequently, it is not necessary to include every detail of the analyzed processes, which would lead to more detail regarding process alternatives while allowing these alternatives to remain unchanged. An example of how we have reduced the level of detail in the model is our simulation time of six days. We do not consider deliveries on Sundays, when stores are closed. Thus, we assume that products ordered on Saturdays are delivered on Mondays. Allowing deliveries on Sundays would simply increase the differences between the process alternatives (e.g., flow times or stock levels).

We ran 1,000 simulations and present the mean values, standard deviations, and minimum and maximum values of the relevant output parameters. We ran 12 scenarios, four for each store format, as follows:

- Scenarios 1-3: In these scenarios, we assume that the cold rooms and shelves are in their initial, basic state $(1=$ supermarket, 2 = small hypermarket, 3 = large hypermarket $)$.

- Scenarios 4-6: All deliveries are assumed to be on time (4 = supermarket, $5=$ small hypermarket, 6 = large hypermarket).

- Scenarios 7-9: Disposal/recycling is reduced by $75 \%$ (7 = supermarket, $8=$ small hypermarket, $9=$ large hypermarket).

- Scenarios 10-12: Substantial changes are made to the processes. The cold room is removed and, consequently, all products are stored on the shelves (i.e., chilled cabinets). The order policy is also adapted for all three store formats as shown in Table 8 below (10 = supermarket, $11=$ small hypermarket, 12 = large hypermarket) 
We assumed for all scenarios a simple periodic $(\mathrm{t}, \mathrm{S})$ replenishment policy (Silver et al. 1998) although a continuous replenishment policy would perform better (Cachon 2001) in reality this simple policy is dominating. This policy means that, each day, an order is placed according to the current inventory level (i.e., the stock in the store plus any ordered stock that has not yet been taken to the storage room) and the target inventory level.

Stock replenishment $\left(\mathrm{RO}_{\mathrm{ti}}\right)$ is based on demand per day $\left(\mathrm{CO}_{\mathrm{ti}}\right)$ and disposal/recycling $\left(\mathrm{DR}_{\mathrm{ti}}\right)$, as illustrated in (6). $\mathrm{SH}_{\mathrm{ti}}$ is the actual inventory at the end of period $\mathrm{t}$, without backorders.

$$
\begin{aligned}
& R O_{t i}=S-S H_{t i} \\
& S H_{t i}=S H_{t i-\Delta t}-C O_{t i}+P_{t i}\left(1-\frac{D R_{t i}}{100}\right) \text { for } I_{t i}=I I_{t i}=C R_{t i}=I I I_{t i}=0 \\
& P_{t i}=R O_{t i-\Delta t}
\end{aligned}
$$

Table 8 shows the initial stock levels in the storage rooms, i.e. buffer in front of the receiving inspection $\mathrm{I}_{00}$, inspection and transport to cold room $\mathrm{II}_{00}$, cold room $\mathrm{CR}_{00}$, buffer in front of handling and storage $\mathrm{III}_{00}$, shelf $\mathrm{SH}_{00}$. They are calculated assuming a $99.9 \%$ cycle service level. In scenarios $1-9$, the shelf is constantly replenished from the cold room (i.e., the stock level is checked regularly and replenished accordingly). Due to the elimination of this step in scenarios 10-12, the control and replenishment of stock levels happens only once per day. 
Table 8: Initial stock levels in the storage rooms

\begin{tabular}{lccccc}
\hline \multicolumn{7}{c}{ Scenarios 1-9 } \\
\hline Store format & $\mathrm{I}_{00}$ & $\mathrm{II}_{00}$ & $\mathrm{CR}_{00}$ & $\mathrm{III}_{00}$ & $\mathrm{SH}_{00}$ \\
\hline Supermarket & 0 & 0 & 36 & 0 & 56 \\
Small hypermarket & 0 & 0 & 46 & 0 & 92 \\
Large hypermarket & 0 & 0 & 55 & 0 & 99 \\
\hline \multicolumn{7}{c}{$\mathrm{Scenarios} \mathrm{10-12}$} & $\mathrm{CR}_{00}$ & $\mathrm{III}_{00}$ & $\mathrm{SH}_{00}$ \\
\hline Store format & $\mathrm{I}_{00}$ & $\mathrm{II}_{00}$ & - & 0 & 83 \\
\hline Supermarket & 0 & - & - & 0 & 115 \\
Small hypermarket & 0 & - & - & 0 & 138 \\
Large hypermarket & 0 & - & & & \\
\hline
\end{tabular}

Figure 5 shows the results for a selection of performance measures that we used for the process analysis, related to potential areas of improvement. To test our research proposition (that lower efficiency can be achieved through different configurations), we selected time-related performance measures (flow time - cold room, flow time - total, and flow time $>72$ hours). The latter is critical in this context because fresh milk cannot be sold after it has been in the store for 72 hours (total store flow time). We also consider one performance measure related to the shelf inventory, SH. Based on these performance measures, we can analyze the relevant cost drivers (inventory plus total flow time $>72$ hours) and revenue drivers (flow time - total which is related to customer satisfaction). 

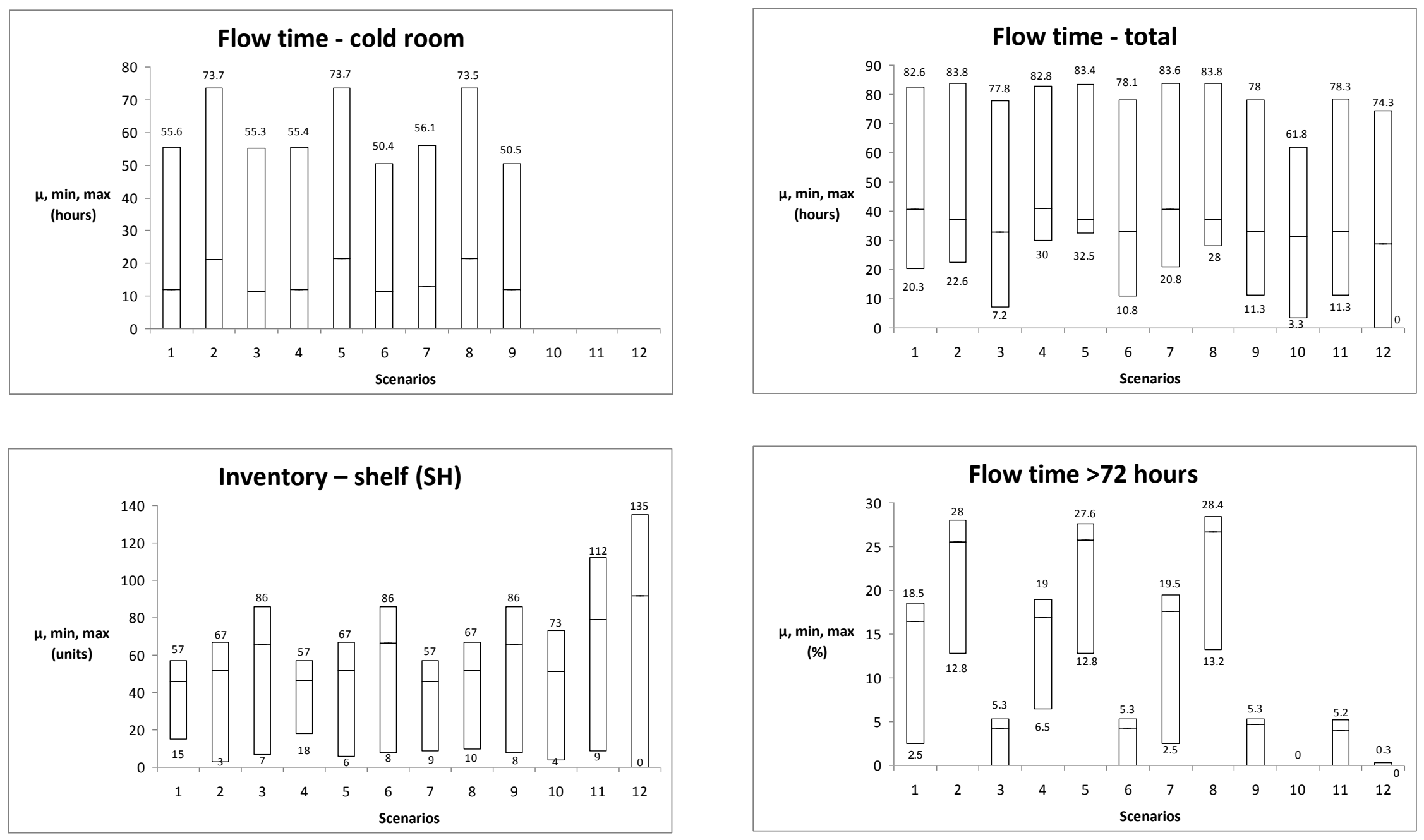

Figure 5: Results from the simulation analysis 
The results for the basic scenarios (1-3) show that when products spend longer in the supermarket (scenario 1) and the large hypermarket (scenario 3). This is primarily caused by the tactical design of the order policy (reorder time, order period, safety factor, etc.) and is not influenced considerably by the large distances in the stores. In scenario 2 , in the setting of the small hypermarket, the share of products with a flow time of more than 72 hours is higher than in scenario 1, although the average flow time is lower. This observation confirms our findings in the DEA regarding the problems that can occur in hypermarkets. In other words, the significant performance differences identified for format small hypermarket leading to lower efficiency could be caused by different configurations, such as in-store transport distances, in this format.

Our respondents raised a number of issues related to in-store logistics, such as delays in deliveries, and damage to products. These issues seem to have no substantial impact on performance. Significant improvements can only be achieved by making substantial process changes, such as eliminating cold rooms (i.e., as in scenarios 10-12). In other words, the products need to be brought directly to the chilled cabinets without being stored first. This would reduce the maximum and average flow times but also considerably decrease the average stock level. These measures are the most important for financially evaluating in-store logistics, as they relate to storage and disposal/recycling costs. The disadvantage in removing the cold room is that additional shelf storage space is needed - approximately $49 \%$ in supermarkets, $25 \%$ in small hypermarkets, and $40 \%$ in large hypermarkets.

Finally, based on the simulation analysis, we are not able to reject the proposition that lower efficiency is caused by different format configurations. In particular, the critical performance (flow time $>72$ hours) of format small hypermarket is significantly worse than those of the other two formats. 


\section{Conclusions}

In this penultimate chapter we discuss our findings from the various analyses and highlight the contributions of this paper to both theory and practice.

\subsection{Contributions and implications for theory}

By addressing Frei and Harker's (1999) critique of a lack of insights into the relationships between inputs and outputs, the first theoretical contribution of this paper lies in the investigation of the efficiency levels of in-store logistics systems using DEA, and the subsequent identification of areas for improvement in in-store logistics processes. Our empirical results show that the efficiency of these processes varies among store formats.

We see acceptable input-output ratios for both smaller formats (supermarkets) and larger formats (large hypermarkets). However, the hybrid store format (small hypermarkets) exhibited comparatively worse performance. The differences in these efficiency levels is interpreted from Fisher et al.'s (2006) view of a store as a combination of a factory (production/input side) and a sales office (distribution/output side) where production capacity - personnel, space, store infrastructure and product range - needs to be balanced against the output requirements, such as sales, service level and disposal/recycling. In our study setting, this balance was achieved relatively well by supermarkets and big hypermarkets, but not at all by small hypermarkets. More generally, this finding indicates the impact of in-store logistics on store performance measures such as turnover, disposal/recycling and out-of-stock rates. The latter measure affects customer satisfaction and arguably store loyalty - both customer-related key performance measures of stores and retailers (Emmelhainz et al. 1991, Corsten and Gruen 2003; Baron et al. 2011). Given this paper's focus on in-store logistics processes, this finding supports the notions of authors dealing with other, more specific in-store logistics-related issues regarding the crucial 
role store operations play for retailers (Raman et al. 2001a, 2001b, Ton and Huckmann 2005, Fisher et al. 2006, van Donselaar et al. 2006, 2010, DeHoratius and Raman 2007).

Our second theoretical contribution relates to our process simulation, conducted to provide a better understanding of the sources of the differences in performance levels. In line with Raman et al. (2001a), we see that the strategic and tactical configuration of in-store logistics processes, such as store design and order policies, affects the (logistics) service level. Marginal improvements in performance figures can be expected through reducing delivery delays and damage to products. In terms of out-of-stock situations, this finding supports Corsten and Gruen (2003), who reveal that store operations and in-store logistics are core improvement areas for increasing on-shelf availability. In the context of the presented research study, we must emphasize that fundamental performance improvements can be reached only through substantial process modifications, for example, if all products are stored directly on a shelf or in a chilled cabinet without being stored first in a cold room.

This final set of findings demonstrates the value of process simulation for generating further insights. This third theoretical contribution of this paper is a methodological one and relates to the applied multi-analysis approach. We can confirm Davis et al.'s (2007) and Bertrand and Fransoo's (2002) view on the benefits of quantitative, model-driven empirical research and conclude that our approach proved to be highly appropriate for investigating efficiency and areas for improvement in in-store logistics systems based on survey data. Similar or related in-store logistics settings could be investigated using the same descriptive framework, the empirical research method and a combination of DEA and process simulation.

Our in-store logistics process framework represents our fourth contribution. It can be used to structure in-store logistics processes and suggests particular input and output measures as 
presented in the third section of this paper (see also Tables 1 and 2 as well as Figure 1). This framework enables the researcher to evaluate in-store logistics processes simply. The framework could also be used for other product and retail categories (e.g. non-chilled/frozen food, or nonfood products in grocery retailing, fashion retailing, etc.).

The final contribution of this research is the development of a questionnaire with openended and closed questions, based on the abovementioned framework (see appendix). We used the questionnaire to examine the execution of in-store logistics processes for the dairy category in 202 different stores of a single grocery retailer. The results reveal the challenge inherent in making products available to customers, using the limited resources of the retail outlet. Ultimately these findings confirm Raman et al.'s (2001a, 2001b) view that there are considerable problems relating to logistics processes, such as suboptimal store designs, the lack of on-shelf availability and wastage.

\subsection{Implications for practice}

As Fisher (2009, p. 529) points out, “.... retailers care most about results, so any use of science that can demonstrate a significant improvement in results will get a serious look from retailers...." Our results are also very relevant for retailers, as the following implications for store management in general and in-store logistics management in particular reveal:

Getting the store configuration right: Despite their connection to the in-store logistics part of store operations, the identified inefficiencies related to the hybrid format, i.e. the small hypermarket, show that the retail management has not provided the right conditions to allow logistics to meet the necessary output level. Practitioners should carefully consider what is an appropriate store process configuration, in the sense of achieving a balance between input (e.g. floor space, number of employees, stock keeping units, store layout) and output (e.g. service 
level, turnover). Since the replenishment of products in-store mainly includes manual-handling activities, store personnel are arguably the most important input factor influencing service levels.

Changes in the replenishment process: The analysis based on the process simulation reveals that a significant impact on output measures can be achieved by eliminating the stage of storing products in the cold room (back room storage facility) and, at the same time, streamlining the processes and increasing the shelf space for products. In practice, this indicates the necessity of having as much stock as possible available at the point of sale instead of stored in the back room area and thus not contributing to store performance. This can be achieved by increasing the shelf space physically and introducing clever storage solutions such as deeper cabinets, using the gravity of the products to replenish automatically. Already frequently used in bigger store formats, chilled cabinets could be used that can replenished from the back. Such storage devices increase the convenience and pace of stacking shelves and ensure that store personnel do not get in the way of customers. Finally, and probably most importantly, these results suggest that stores should make better use of shelf space by focusing on those products that are preferred by the consumers. Category management projects should be used to critically identify those products within each product category that do not provide sufficient space productivity (Kurtuluş and Toktay 2011). Such products could then be eliminated to make room for other more popular and profitable ones.

Redesign of replenishment processes: Both the descriptive and modeling results call for the requirements of the replenishment process to be considered in designing the layouts of stores. Thus, store design should not only consider customer needs but also logistics requirements so as to enable the trouble-free replenishment of products. Apart from the physical layout, practitioners should be aware that the tactical design of the order policy has a major impact on 
the service level. This calls for a critical evaluation of reorder times (averages and variability), order periods and safety factors. This in turn should influence the evaluation and selection of suppliers, that is, logistic performance factors should be emphasized as well as or instead of a simple cost(price)-cutting strategy.

\section{Limitations and further research directions}

This final section highlights the limitations of our findings and recommends further research ideas. We have focused our study and analysis on in-store logistics processes related to dairy products. The external validity of our results is consequently limited to those items with similar product and turnover characteristics. Research on other product categories with lower turnover and that are less sensitive, such as those with lower perishability or less-sensitive packaging, may show different results. By applying our proposed analysis path, future researchers could focus on product categories such as beverages, canned food, fruits and vegetables, or non-food categories. The study could also be replicated for other important retail industries, e.g., fashion or consumer electronics, and other dominant store formats, e.g., category killers, convenience, discount or department stores.

Our analysis approach is limited in terms of the performance measures we used. We did not investigate financial performance measures, but we can assume that the performance measures we did use are cost drivers as well as indicators of revenue. Some of our managerial implications would be difficult (or expensive) to implement, such as the elimination of backroom storage, but it should be easy to consider these research results when designing new stores. A further limitation is that we carried out our process simulation for just one specific product (fresh milk). Further analysis could deal with different product characteristics. 


\section{References}

Banker, R., A. W. Charnes, W. Cooper. 1984. Some models for estimating technical scale inefficiencies in data envelopment analysis. Management Science 30(9) 1078-1092.

Banker, R., R. Morey. 1986. Efficiency analysis for exogenously fixed inputs and outputs. Operations Research, 34(4) 513-521.

Baron, O., O. Berman, D. Perry. 2011. Shelf space management when demand depends on the inventory level. Production and Operations Management 20(5) 714-726.

Bertrand, J. W. M., J. C. Fransoo. 2002. Modelling and simulation: Operations management research methodologies using quantitative modelling. International Journal of Operations and Production Management 22(2) 241-264.

Broekmeulen R., K. H. van Donselaar, J. C. Fransoo, T. van Woensel. 2004. Excess shelf space in retail stores: An analytical model and empirical assessment, BETA working paper, series 109, Eindhoven, http://beta.ieis.tue.nl/node/1314, retrieved 29 August 2012.

Cachon, G. 2001. Managing a retailer's space, inventory, and transportation. Manufacturing and Services Operations Management 3(3) 211-229.

Charnes, A., W. W. Cooper, E. Rhodes. 1978. Measuring the efficiency of decision making units. European Journal of Operations Research 2(6) 429-444.

Clarke, R. L., K. N. Gourdin. 1991. Measuring the efficiency of the logistics process. Journal of Business Logistics 12(2) 17-33.

Cooper, W. W., L. M. Seiford, K. Tone. 2007. Data Envelopment Analysis: A Comprehensive Text with Models, Applications, References and DEA-solver Software. Kluwer Academic Publishers, Norwell, MA. 
Corsten, D., T. Gruen. 2003. Desperately seeking shelf availability: An examination of the extent, the causes, and the efforts to address retail out-of-stocks. International Journal of Retail and Distribution Management 31(12) 605-617.

Coughlan, A. T., Anderson, E., Stern, L. W., El-Ansary, A. 2006. Marketing Channels. Pearson Prentice Hall, Upper Saddle River (NJ).

Curşeu, A., T. van Woensel, J. C. Fransoo, K. van Donselaar, R. Broekmeulen. 2009. Modelling handling operations in grocery retail stores: An empirical analysis. Journal of the Operations Research Society (UK) 60(2) 200-214.

Davis, J. P., K. M. Eisenhardt, C. B. Bingham. 2007. Developing theory through simulation methods. Academy of Management Review 32(2) 480-499.

DeHoratius, N., A. Raman 2007. Store management incentive design and retail performance: An exploratory investigation. Manufacturing and Services Operations Management 9(4) 518534.

Dyson, R. G., R. Allen, A. S. Camanho, V. V. Podinovski, C. S. Sarrico, E. A. Shale. 2001. Pitfalls and protocols in DEA. European Journal of Operations Research 132(2) 245-259.

Emmelhainz, L. W., M. A. Emmelhainz, J. R. Stock. 1991. Logistics implications of retail stockouts. Journal of Business Logistics 12(2) 129-142.

Ferguson, M., M. E. Ketzenberg. 2006. Information sharing to improve retail product freshness of perishables. Production and Operations Management 15(1) 57-73.

Fisher, M. 2009. Rocket science retailing. The 2006 Philip McCord Morse lecture. Operations Research 57(3) 527-540.

Fisher, M., A. Raman, A. McClelland. 2000. Rocket science retailing is almost here - are you ready? Harvard Business Review 78(4) 115-124. 
Fisher, M., J. Krishan, S. Netessine. 2006. Retail store execution: An empirical study, http://knowledge.wharton.upenn.edu/papers/1336.pdf, retrieved 29 August 2012.

Frei, F., P. Harker. 1999. Measuring the efficiency of service delivery processes. Journal of Services Research 1(4) 300-312.

Kotzab, H., P. Schnedlitz. 1999. The integration of retailing to the general concept of supply chain management. Journal für Betriebswirtschaft 49(4) 140-153.

Kurtuluş, M., L. B. Toktay. 2011. Category captainship vs. retailer category management under limited retail shelf space. Production and Operations Management 20(1) 47-56.

Li, Y., B. Cheang, A. Lim. 2012. Grocery perishables management. Production and Operations Management 21(3) 504-517.

Liebmann, H. P., J. Zentes. 2001. Handelsmanagement [Retail management], Vahlen, Munich. Metters, R. C., F. X. Frei, V. A. Vargas. 1999. Measurement of multiple sites in service firms with data envelopment analysis. Production and Operations Management 8(3) 264-282.

Quinn, F. 2006. Crowning the Customer. How to Become Customer-driven, O'Brien, Dublin.

Raman, A., N. DeHoratius, T. Z. Ton. 2001a. Execution: The missing link in retail operations. California Management Review 43(3) 136-152.

Raman, A., N. DeHoratius, T. Z. Ton. 2001b. The Achilles heel of supply chain management. Harvard Business Review 79(5) 25-28.

Reiner, G., P. Hofmann. 2006. Efficiency analysis of supply chain processes. International Journal of Production Research 44(23) 5065-5087.

Roll, Y., W. D. Cook, B. Golany. 1991. Controlling factor weights in data envelopment analysis. IIE Transactions 23(1) 2-9. 
Scheel, H. 2001. Undesirable outputs in efficiency valuations. European Journal of Operations Research 132(2) 400-410.

Silver, E. A., D. F. Pyke, R. Peterson. 1998. Inventory Management and Production Planning and Scheduling. John Wiley and Sons, New York.

Sudit, E. F. 1995. Productivity measurement in industrial operations. European Journal of Operations Research 85(3) 435-453.

Talluri, S., R. C. Baker. 2002. A multi-phase mathematical programming approach for effective supply chain design. European Journal of Operations Research 141(3) 544-558.

Tavares, G. 2002. A bibliography of data envelopment analysis (1978-2001). RUTCOR Research Report, RRR 01-02, Rutgers Centre for Operations Research, Rutgers University, New Jersey, http://rutcor.rutgers.edu/pub/rrr/reports2002/1_2002.pdf, retrieved 29 August 2012.

Ton, Z., R. S. Huckman. 2005. Managing the impact of employee turnover on performance: The role of process conformance. Working paper, Harvard University, Boston, MA.

Tone, K. 2001. Retailing, S. I. Gass, C. M. Harris, eds. Encyclopedia of Operations Research \& Management Science. Kluwer Academic Publishers, Norwell, MA, 718-719.

van Donselaar, K., T. van Woensel, R. C. M. Broekmeulen, J. C. Fransoo. 2006. Inventory control of perishables in supermarkets. International Journal of Production Economics 104(2) 462-472.

van Donselaar, K., V. Gaur, T. van Woensel, R. C. M. Broekmeulen, J. C. Fransoo. 2010. Ordering behavior in retail stores and implications for automated replenishment. Management Science 56(5) 766-784. 
van Zelst, S., K. van Donselaar, T. van Woensel, R. Broekmeulen, J. C. Fransoo. 2008. Logistics drivers for shelf stacking in grocery retail stores: Potential for efficiency improvement. International Journal of Production Economics 121(2) 620-32.

Vaz, Z., A. S. Camanho, R. Guimarãs. 2010. The assessment of retailing efficiency using network data envelope analysis. Annals of Operations Research 173(1) 5-24. 


\section{Appendix}

The following questions represent an excerpt of the used interviewer administered questionnaire. The respondents/informants were guided through the in-store logistics processes as described in Table 1. Interviewers used pictures of dairy products and graphical representations of the applied scales to support the survey process.

Receipt/inspection

R1: How often are dairy products delivered to your store per day?

R2a: How often are deliveries checked and inspected per week?

$\mathrm{R} 2 \mathrm{~b}$ : How long does is take on average to check and inspect the products delivered to your store?

Transport of tertiary packaging units to cold room or directly to shelves

Ta1: What is the maximum/minimum amount of time necessary to replenish the shelves as soon as the products are delivered to the store? (Storage time in cold rooms were excluded, both time intervals estimated separately in minutes)

Ta2: How far away is the cold storage room from the incoming dock of the store? (Estimated in meters)

Ta2: How far away are the chilled cabinets from the incoming dock of the store? (Estimated in meters)

Storage of tertiary packaging units in cold room

ST1: How big is the cold storage room? (Estimated in square meters)

ST2: How long are dairy products stored in the cold storage room on average? (Estimated for different types of dairy products in hours)

Transport from cold room to shelves

Tb1: How far away is the cold storage room from the chilled cabinets? (Estimated in meters)

Break bulk of tertiary packaging, and handling and storing of stock-keeping units on shelves

B1: How often per day are chilled cabinets replenished with dairy products?

B2: How many hours does this replenishment process take per day?

B3: How many work hours are necessary to replenish the products per day?

Re-ordering

R1: How often are dairy products re-ordered per day?

R2: How long does it takes in minutes to re-order products?

Disposal/Recycling/Service level

D1: What is the share of dairy products that arrive damaged at the store?

D2: What share of dairy products in terms of quantity is disposed every day? (Estimation in per cent per day) 
D3: What share of dairy products in terms of value is disposed every day? (Estimation in per cent per day)

Service level

D4: How often are the following products out-of-stock both in the shelves and in the store? (Estimated for each dairy product based on a five point rating scales; 1, very frequent out of stock; 5, never out of stock).

Store characteristics

C1: What is the size of the store in total - including all rooms, e.g. back office, storage room etc.? (Estimation in meters squared)

C2: What is the size of the sales floor? (Estimation in meters squared)

C3: What is the width of the chilled cabinets in meters?

C4: How much staff works in this store? (Number estimated for full-time, part-time employees separately)

C5: What is the number of stock keeping units in the dairy category offered in this store? 